\title{
Prevalence of Masked Obesity Associated with Lifestyle-Related Habits, Dietary Habits, and Energy Metabolism in Japanese Young Women
}

\section{Noriko Tanaka $^{1,11^{*}}$, Toyoko Okuda ${ }^{2}$, Hisae Shinohara ${ }^{3}$, Naomi Hirano ${ }^{4}$, Yuko Higashine ${ }^{5}$, Ikue Hamaguchi ${ }^{6}$, Jangmi Kang ${ }^{7}$, Yasuyo Asano ${ }^{8}$, Mami Umemoto ${ }^{9}$, Mitsue Sakakihira ${ }^{1}$, Nao Nishioka ${ }^{10}$, Kazue Komorizono ${ }^{11}$}

\author{
${ }^{1}$ Faculty of Home Economics, Kobe Women's University, Kobe, Hyogo 654-8585, Japan \\ ${ }^{2}$ Tezukayamagakuin University (Former professor), Sakai, Osaka 590-0113, Japan \\ ${ }^{3}$ Faculty of Education, University of Miyazaki, Miyazaki 889-2192, Japan \\ ${ }^{4}$ Department of Food and Nutrition Sciences, Kobe Women's Junior College, \\ Kobe, Hyogo 650-0046, Japan \\ ${ }^{5}$ Faculty of Clinical Nutrition and Dietetics, Konan Women's University, Kobe, Hyogo 658-0001, Japan \\ ${ }^{6}$ Faculty of Human Sciences, Konan Women's University, Kobe, Hyogo 658-0001, Japan \\ ${ }^{7}$ Department of Nutrition, Hyogo NCC College, Nishinomiya, Hyogo 662-0833, Japan \\ ${ }^{8}$ Kio University (Former professor), Nara 635-0832, Japan \\ ${ }^{9}$ Department of Food and Nutrition Sciences, Osaka Yuhigaokagakuen Junior College, \\ Osaka 543-0073, Japan \\ ${ }^{10}$ Principal of Kobe International Cooking and Pastry College, Nishinomiya, Hyogo 662-0833, Japan \\ ${ }^{11}$ Graduate school of Life Sciences, Kobe Women's University, Kobe, Hyogo 654-8585, Japan
}

\begin{abstract}
We investigated the prevalence of Masked Obesity (MO) and the correlations between MO and lifestylerelated habits (e.g., exercise habits, dieting habits), dietary habits, energy metabolism, and seasons. The subjects were 131 young Japanese college students. Body composition was measured by bioelectrical impedance method and Resting Metabolic Rate (RMR) was measured by an indirect calorimeter. Subjects with a BMI in the normal range $(\mathrm{n}=110)$ were divided into the MO (percentage of body fat to Body Weight $[\mathrm{BF}] \geq 30 \%)$ and control $(\mathrm{C})(\mathrm{BF}<30 \%)$ groups. Dietary energy and nutrient intakes were calculated from weighed dietary records. A questionnaire on lifestyle habits was obtained individually from the subjects. The percentage of MO was $32 \%$ of subjects within normal BMI. The prevalence of MO was the highest in winter, probably due to accumulation of body fat as an adaptation to cold. The MO group had low Fat-Free Mass (FFM) and high BF. RMR of the MO group was significantly lower than that of the $\mathrm{C}$ group. The MO group tended to have poor exercise habits, more dieting (restricting calorie intake) experiences and consumed a diet with less vegetables and beans. We concluded that the prevalence of MO was $32 \%$; it was the highest in winter for subjects who had high fat and low FFM. This fact may be due to poor exercise, more dieting experiences and insufficient intake of vegetables and beans. Furthermore, this accumulation of body fat may be partly due to low RMR.
\end{abstract}

Keywords: body mass index, energy metabolism, life-related habits, masked obesity, seasonal variation

\section{INTRODUCTION}

Body Mass Index (BMI: expressed as body weight in kilograms divided by height in meters squared, $\mathrm{kg} / \mathrm{m}^{2}$ ) is a useful tool for defining anthropometric characteristics and determining obesity. However, a disadvantage of BMI is that it does not reflect the precise levels of body fat. Recently, obesity has been found in young Japanese women whose BMI is in the normal range $\left(18.5 \leq \mathrm{BMI}<25 \mathrm{~kg} / \mathrm{m}^{2}\right)$, but have a relatively high percentage of body fat based on Japanese standards. This phenomenon called "masked obesity" has been detected often (Takahashi et al. 2002), and its prevalence is growing. It has been suggested that masked obesity is associated with a higher risk of developing serum lipid abnormalities, arteriosclerosis, and obesity. Additionally, obesity at a young age is associated with high morbidity and mortality due to arteriosclerotic disease, even if obesity is improved in adulthood (Must et al.1992). Masked

"Corresponding Author: tel: +8178-737-2434, email: norikota@suma.kobe-wu.ac.jp 
obesity is not easily detected on the basis of BMI alone; thus, body composition measurements are necessary for early detection of this condition (Oguri et al. 2006).

It has been speculated that masked obesity may be caused by young women consuming inappropriate diets and maintaining sedentary lives (Yoshiike et al. 2002). Yoshiike et al. found that the mean BMI of women aged 20 to 39 years in the National Health and Nutrition Examination Survey decreased between 1976 and 1995. In addition, the percentage of women in their twenties who were underweight $(\mathrm{BMI}<18.5 \mathrm{~kg} /$ $\mathrm{m}^{2}$ ) was $13.4 \%$ in 1981 ; however, since then it increased continuously to $21.7 \%$ in 2016 , with one in five young women being underweight (2017 National Health and Nutrition Examination Survey). Reports have suggested that increased thinness may be influenced by inappropriate dieting behaviors associated with young people's desire to be thin (Mase et al. 2012) and that these dieting habits may make small Fat-Free Mass (FFM) more likely to accumulate as body fat and influence the formation of masked obesity. This is because, in the case of normal body weight with low or normal body fat, energy restriction such as dieting will induce a greater loss of lean mass than body fat (Dulloo \& Jacquet 1999).

Body composition and nutritional status (McKinney et al. 2008) change seasonally, and body weight, fat mass, and fat percentage are known to increase during the winter and decrease during the summer in young Japanese women (Yumigeta et al. 2015). Subcutaneous fat gain in winter (Ishigure et al. 1980) is an important adaptation to the cold environment (Glaser \& Shephard 1963). It is unclear, however, whether seasonal changes in body fat are associated with the prevalence and development or improvement of masked obesity.

This study aimed to examine the prevalence of masked obesity and to comprehensively assess whether masked obesity is associated with lifestyle-related habits, eating habits, energy metabolism, and seasons.

\section{METHODS}

\section{Design, location, and time}

Participants were 131 female students in the fourth year who belong to the Faculty of Home Economics at a university in Kobe and live in the Kansai area (south-western half of Japan including Kobe or Osaka city). The study was conducted in the spring of 2015 and 2016. Twenty five subjects participated in a one year study investigating seasonal changes in body fat percentage in winter, spring, summer, and autumn of 2015-2016. Seasonal variation in the prevalence of masked obesity was examined from the body fat percentage. Informed consent was obtained in advance by explaining the aim and method of the study. This study was approved by the Human Ethics Research Committee of Kobe Women's University.

\section{Sampling}

Of the total participants, 14 students $(10.7 \%)$ had a $\mathrm{BMI}<18.5 \mathrm{~kg} / \mathrm{m}^{2}$, and 7 students $(5.3 \%)$ had a $B M I \geq 25 \mathrm{~kg} / \mathrm{m}^{2}$. Data from these students $(\mathrm{n}=21)$ were excluded, thus data from the subjects with a BMI in normal range $(\mathrm{n}=110)$ were extracted for the study.

\section{Definition of masked obesity and the categories}

Masked obesity was defined as BMI $\left(18.5 \leq \mathrm{BMI}<25 \mathrm{~kg} / \mathrm{m}^{2}\right)$ with percentage of body fat of $\geq 30 \%$ (Fukuoka et al. 2012). Subjects with a BMI in the normal range were divided into two groups: the masked obesity (MO: body fat $\geq 30 \%$ ) group and the control (C: body fat $<30 \%$ ) group.

\section{Data collection}

Body composition was measured by Inbody 720 (Biospace, Tokyo, Japan) using the bioelectrical impedance method. The measurements by the instrument are highly correlated with the underwater weighing method and Dual-energy X-ray absorptiometry (DEXA) methods (Utter \& Lambeth 2010; Cha et al. 1995; Malavolti et al. 2003). Therefore, the body composition analyzer was used for these measurements.

Body weight and body composition were measured for three consecutive days during the low basal body temperature period, immediately after the end of menstruation for each subject, and the mean value was used for the data. Measurements were performed under the following conditions: 3 hours after breakfast, after urinary and fecal excretion, and with changing into an examination suit.

Resting metabolic rate was measured at the same time as body composition, during the low 
basal body temperature phase, to avoid the effect of sex hormones. Measurements were performed using a metabolic analyzer (MedGem+, MP Japan Co. Ltd.) while subjects were sitting in chairs and resting for about $10 \mathrm{~min}$.

Dietary surveys were conducted on three consecutive days during the low basal temperature period (along with body composition measurements), using the self-weighing records method. Subjects were asked to use their dietary record forms and leaflets to document all of the ingredients and seasonings used as well as their weights. For the marketed products, the trade name, brand name, and amount of energy and nutrients displayed were recorded. Nutrition calculations were performed using Excel Eiyoukun Ver.6.0 (Kenpakusha, Tokyo, Japan), and energy/nutrient intake per day was calculated.

A questionnaire survey was conducted to investigate lifestyle and dietary habits associated with masked obesity. Questionnaire items were related to dieting experience, and past and current exercise habits. Questionnaires were distributed at the time of body composition measurement; they were self-completed and collected on the same day.

\section{Data analysis}

IBM SPSS, Ver. 21 (IBM Corp., Armonk, NY, USA) was used for statistical analysis. An unpaired t-test was used for testing between the two groups, a chi-square test was used for crosstabulation, and a Pearson test for correlation. The level of significance was less than $5 \%$.

\section{RESULTS AND DISCUSSION}

\section{Physique of the subjects and prevalence of masked obesity}

The subjects with a BMI in normal range $(\mathrm{n}=110)$ were extracted from the participants $(\mathrm{n}=131)$. Their height, weight, BMI, body fat, and fat-free mass are shown in Table 1. The height and weight of the subjects were within the range of body sizes in the results of the National Health and Nutrition Examination Survey in Japan (MoHWL 2017) aged 20-29 years (Table $1)$. Thus, the BMI of the subjects was $21.1 \pm 1.5$ $\mathrm{kg} / \mathrm{m}^{2}$, which was similar to the BMI $(20.6 \pm 3.3$ $\mathrm{kg} / \mathrm{m}^{2}$ ) of the National Survey data in Japan (MoHWL 2017).

Among the subjects with a normal BMI, the prevalence of masked obesity (\% body fat $\geq 30 \%$ ) was about $32 \%$ in the spring where the experiment started (Figure 1). The prevalence of MO in our study was higher than that of MO reported in 2012 (17.8\%) (Fukuoka et al. 2012) but is almost equivalent to that reported in 2017 (Takeda et al. 2017). The frequency of masked obesity seems to increase year by year. As masked

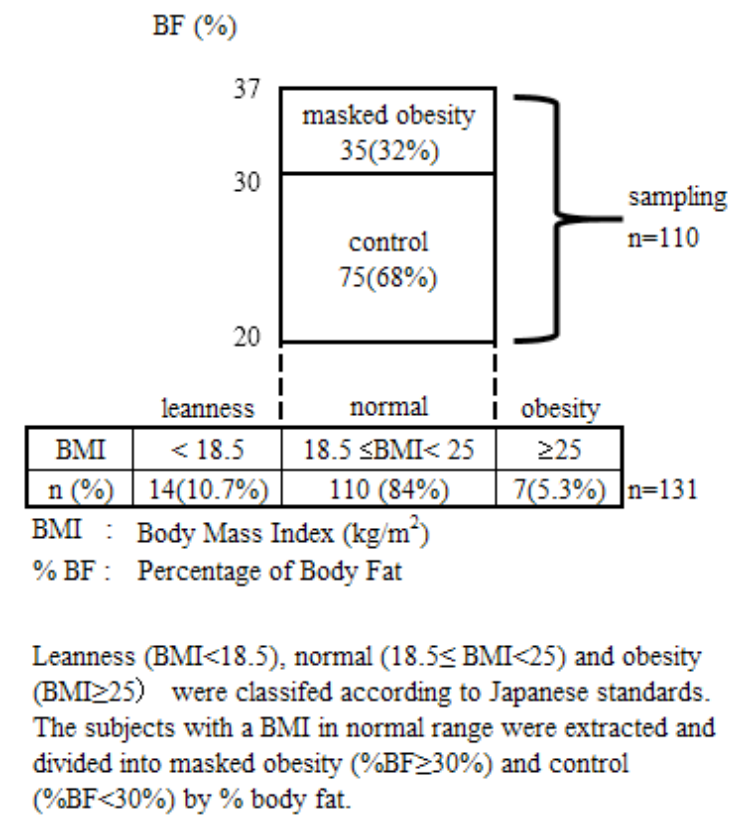

Figure 1. BMI distribution in participants $(\mathrm{n}=131)$ and classification of the subjects with a normal range of BMI by $\%$ body fat 
Tanaka et al.

Table 1. Physical characteristics of subjects

\begin{tabular}{|c|c|c|c|}
\hline \multirow{2}{*}{ Anthropometric parameters } & \multirow{2}{*}{ Subjects } & \multicolumn{2}{|c|}{ Value } \\
\hline & & Minimum & Maximum \\
\hline Height $(\mathrm{cm})$ & $158.1 \pm 5.0$ & 146 & 169.4 \\
\hline Weight $(\mathrm{kg})$ & $52.8 \pm 5.1$ & 42.3 & 66.3 \\
\hline $\operatorname{BMI}\left(\mathrm{kg} / \mathrm{m}^{2}\right)$ & $21.1 \pm 1.5$ & 18.5 & 24.7 \\
\hline Muscle mass (kg) & $35.38 \pm 3.24$ & 28.8 & 44 \\
\hline Skeletal muscle mass $(\mathrm{kg})$ & $20.43 \pm 2.08$ & 16.1 & 25.8 \\
\hline Fat-free mass $(\mathrm{kg})$ & $37.81 \pm 3.45$ & 30.7 & 47 \\
\hline Body fat mass $(\mathrm{kg})$ & $14.96 \pm 3.00$ & 9.7 & 24.1 \\
\hline Body fat percentage $(\%)$ & $28.21 \pm 3.93$ & 19.57 & 37.1 \\
\hline Body water content (1) & $27.72 \pm 2.55$ & 22.5 & 34.3 \\
\hline Intra cellular water content (l) & $17.20 \pm 1.59$ & 13.9 & 21.4 \\
\hline Extra cellular water content (l) & $10.49 \pm 0.93$ & 8.6 & 12.9 \\
\hline Protein weight $(\mathrm{kg})$ & $7.44 \pm 0.69$ & 6.0 & 9.2 \\
\hline Mineral amount (kg) & $2.69 \pm 0.25$ & 2.26 & 3.48 \\
\hline Waist hip ratio & $0.81 \pm 0.29$ & 0.75 & 0.88 \\
\hline RMR (kcal/day) & $1,039 \pm 120$ & 780 & 1,330 \\
\hline
\end{tabular}

Values are means \pm Standard deviation (SD) (n=110); RMR: Resting Metabolic Rate; BMI: Body Mass Index The subject with a normal range of BMI $(18.5 \leq \mathrm{BMI}<25)$ were extracted in the study

obesity cannot be detected without measuring body composition, some people with MO may remain unaware that their health is at risk. Hence, obesity awareness is important for preventing the development of obesity (Akil \& Top 2019).

\section{Comparison of body composition between masked obesity and normal individuals}

Body compositions and resting metabolic rate of the MO group were compared with those of the $\mathrm{C}$ group (Table 2).

There was no significant difference between the $\mathrm{MO}$ and $\mathrm{C}$ groups in height, but body weight was significantly greater by $3.1 \mathrm{~kg}$ in the $\mathrm{MO}$ group than in the control. The BMI $\left(=22 \mathrm{~kg} / \mathrm{m}^{2}\right)$ in the MO group was also significantly greater than that $\left(=20 \mathrm{~kg} / \mathrm{m}^{2}\right)$ in the $\mathrm{C}$ group (Table 2); thus, the BMI in the MO group might be an indicator of masked obesity. In other words, a BMI of 22 in young Japanese women might imply a health risk instead of an appropriate BMI based on the World Health Organization standards (WHO expert consultation 2004). Thus, these results supported a WHO report that Asian populations might have risk factors for diabetes mellitus and cardiovascular disease even below a BMI of 25 $\mathrm{kg} / \mathrm{m}^{2}$ because Asian people generally have a higher body fat than white people of the same BMI(WHO expert consultation 2004).

Comparison of body composition showed that FFM was lower in the MO group by $1.4 \mathrm{~kg}$ than in the $\mathrm{C}$ group $(\mathrm{p}=0.056)$, and the body fat mass was significantly higher by $4.5 \mathrm{~kg}$ in the MO than in the control group $(\mathrm{p}<0.001)$. Thus, 
Table 2. Comparison of body composition and resting metabolic rate between masked obesity group and control group

\begin{tabular}{|c|c|c|c|}
\hline Body composition & $\underset{(\mathrm{n}=35)}{\mathrm{MO}}$ & $\begin{array}{c}\mathrm{C} \\
(\mathrm{n}=75)\end{array}$ & $\mathrm{p}$ value \\
\hline Height (cm) & $157.0 \pm 4.9$ & $158.5 \pm 5.0$ & 0.144 \\
\hline Weight (kg) & $54.9 \pm 5.0$ & $51.8 \pm 4.9$ & 0.002 \\
\hline $\mathrm{BMI}\left(\mathrm{kg} / \mathrm{m}^{2}\right)$ & $22.24 \pm 1.26$ & $20.57 \pm 1.34$ & $<0.001$ \\
\hline Muscle mass (kg) & $34.70 \pm 2.82$ & $35.98 \pm 3.36$ & 0.054 \\
\hline Skeletal muscle mass $(\mathrm{kg})$ & $19.85 \pm 1.76$ & $20.69 \pm 2.17$ & 0.049 \\
\hline FFM $(\mathrm{kg})$ & $36.89 \pm 3.00$ & $38.24 \pm 3.59$ & 0.056 \\
\hline Body fat mass (kg) & $18.03 \pm 2.31$ & $13.53 \pm 2.06$ & $<0.001$ \\
\hline Body fat percentage (\%) & $32.74 \pm 1.84$ & $26.09 \pm 2.63$ & $<0.001$ \\
\hline Right arm muscle mass $(\mathrm{kg})$ & $1.65 \pm 0.21$ & $1.70 \pm 0.24$ & 0.351 \\
\hline Left arm muscle mass $(\mathrm{kg})$ & $1.62 \pm 0.20$ & $1.65 \pm 0.25$ & 0.562 \\
\hline Trunk muscle mass $(\mathrm{kg})$ & $16.15 \pm 1.38$ & $16.33 \pm 1.59$ & 0.556 \\
\hline Right leg muscle mass (kg) & $5.75 \pm 0.64$ & $5.96 \pm 0.69$ & 0.133 \\
\hline Left leg muscle mass $(\mathrm{kg})$ & $5.76 \pm 0.63$ & $5.96 \pm 0.68$ & 0.131 \\
\hline Right arm fat mass $(\mathrm{kg})$ & $1.22 \pm 0.18$ & $0.87 \pm 0.14$ & $<0.001$ \\
\hline Left arm fat mass $(\mathrm{kg})$ & $1.24 \pm 0.19$ & $0.90 \pm 0.14$ & $<0.001$ \\
\hline Trunk fat mass $(\mathrm{kg})$ & $8.60 \pm 1.23$ & $6.22 \pm 1.16$ & $<0.001$ \\
\hline Right leg fat mass $(\mathrm{kg})$ & $2.99 \pm 0.36$ & $2.31 \pm 0.31$ & $<0.001$ \\
\hline Left leg fat mass $(\mathrm{kg})$ & $2.98 \pm 0.36$ & $2.30 \pm 0.30$ & $<0.001$ \\
\hline Waist hip ration & $0.83 \pm 0.03$ & $0.81 \pm 0.03$ & $<0.001$ \\
\hline BMR (kcal) & $1,166 \pm 65$ & $1,196 \pm 77$ & 0.056 \\
\hline RMR (kcal/kg body weight) & $18.93 \pm 1.95$ & $20.19 \pm 2.43$ & 0.008 \\
\hline
\end{tabular}

Values are means $\pm \mathrm{SD}(\mathrm{n}=110)$; Unpaired t test; MO: Masked Obesity group; C: Control group

FFM: Fat-Free Mass; BMR: Basal Metabolic Rate; RMR: Resting Metabolic Rate

we found that the weight gain of masked obesity was due to an increase in body fat that greatly exceeded the decline in fat-free mass.

When comparing body parts, muscle mass in the trunk, and upper and lower limbs, the MO group was almost the same as that of the $\mathrm{C}$ group. On the other hand, body fat mass was significantly greater $(p<0.001)$ in the MO group than in the C group in all body parts, including the trunk, upper limbs, and lower limbs. Approximately 30\%$40 \%$ of fat in the trunk and the upper and lower limbs accumulated more than in the $\mathrm{C}$ group.
Resting metabolic rate was significantly lower in the $\mathrm{MO}$ group than in the $\mathrm{C}$ group. Lower energy metabolism in MO might easily promote fat accumulation.

\section{Energy and nutrient intakes}

Energy intake of the MO group was similar to that of $\mathrm{C}$ group (Table 3 ). Intakes of protein, fat, and carbohydrates in the MO group were also similar to those in $\mathrm{C}$ group. Similarly, the energy composition ratio of fat to total energy in the MO group was not different from that in the 
Tanaka et al.

Table 3. Composition of total energy intake (per day) and nutrient intakes (per day) of between masked obesity group and control group

\begin{tabular}{|c|c|c|c|}
\hline Energy and nutrient intakes & $\begin{array}{c}\mathrm{MO} \\
(\mathrm{n}=35)\end{array}$ & $\begin{array}{c}\mathrm{C} \\
(\mathrm{n}=75)\end{array}$ & $\mathrm{p}$ value \\
\hline Energy (kcal) & $1,434 \pm 320$ & $1,471 \pm 298$ & 0.55 \\
\hline Protein (g) & $53.41 \pm 13.60$ & $55.87 \pm 14.66$ & 0.40 \\
\hline Fat $(g)$ & $50.27 \pm 15.62$ & $49.85 \pm 15.45$ & 0.90 \\
\hline Carbohydrate (g) & $191.61 \pm 52.81$ & $191.04 \pm 45.49$ & 0.95 \\
\hline Protein $(\% \mathrm{E})$ & $14.93 \pm 2.09$ & $15.13 \pm 2.41$ & 0.67 \\
\hline Fat $(\% \mathrm{E})$ & $31.42 \pm 6.42$ & $30.35 \pm 6.63$ & 0.43 \\
\hline Carbohydrate $(\% \mathrm{E})$ & $53.50 \pm 10.00$ & $52.18 \pm 7.79$ & 0.45 \\
\hline Dietary fiber $(\mathrm{g})$ & $7.38 \pm 2.94$ & $9.01 \pm 4.71$ & 0.06 \\
\hline Sodium (mg) & $2384.6 \pm 668.3$ & $2495.9 \pm 776.8$ & 0.47 \\
\hline Potassium (mg) & $1689.1 \pm 662.2$ & $1737.0 \pm 710.2$ & 0.74 \\
\hline Calcium (mg) & $292.8 \pm 128.4$ & $347.8 \pm 153.8$ & 0.07 \\
\hline Magnesium (mg) & $145.5 \pm 42.7$ & $175.3 \pm 72.9$ & 0.01 \\
\hline Phosphorus (mg) & $666.2 \pm 216.7$ & $718.4 \pm 241.1$ & 0.28 \\
\hline Iron $(\mathrm{mg})$ & $4.21 \pm 1.65$ & $5.16 \pm 2.63$ & 0.05 \\
\hline Zinc (mg) & $5.51 \pm 2.08$ & $5.97 \pm 1.92$ & 0.26 \\
\hline Copper (mg) & $0.66 \pm 0.21$ & $0.76 \pm 0.26$ & 0.07 \\
\hline Vitamin $\mathrm{A}(\mu \mathrm{g})$ & $325.9 \pm 216.6$ & $367.4 \pm 254.1$ & 0.41 \\
\hline Vitamin $\mathrm{D}(\mu \mathrm{g})$ & $4.12 \pm 3.09$ & $3.63 \pm 3.38$ & 0.47 \\
\hline Vitamin E (mg) & $4.28 \pm 1.94$ & $4.64 \pm 2.24$ & 0.41 \\
\hline Vitamin $\mathrm{K}(\mu \mathrm{g})$ & $123.6 \pm 73.67$ & $168.4 \pm 251.2$ & 0.31 \\
\hline Vitamin B1 (mg) & $0.67 \pm 0.31$ & $0.67 \pm 0.26$ & 0.99 \\
\hline Vitamin B2 (mg) & $0.82 \pm 0.29$ & $0.86 \pm 0.33$ & 0.52 \\
\hline Niacin (mg) & $19.07 \pm 6.62$ & $21.61 \pm 8.15$ & 0.11 \\
\hline Vitamin B6 (mg) & $0.81 \pm 0.30$ & $0.89 \pm 0.35$ & 0.22 \\
\hline Vitamin B12 $(\mu \mathrm{g})$ & $3.27 \pm 1.93$ & $3.62 \pm 3.42$ & 0.58 \\
\hline Pantothenic acid (mg) & $4.06 \pm 1.46$ & $4.28 \pm 1.52$ & 0.48 \\
\hline Biotin $(\mu \mathrm{g})$ & $21.64 \pm 8.09$ & $26.59 \pm 12.85$ & 0.02 \\
\hline Vitamin C (mg) & $90.27 \pm 113.5$ & $71.12 \pm 44.37$ & 0.34 \\
\hline Salt (g) & $6.10 \pm 1.79$ & $6.32 \pm 2.03$ & 0.58 \\
\hline
\end{tabular}

Values are means $\pm \mathrm{SD}(\mathrm{n}=110)$; Unpaired $t$ test; MO:Masked Obesity group

$\mathrm{C}$ :Control group; Protein $(\% \mathrm{E})$ : The energy composition ratio of protein to total energy; Fat $(\% \mathrm{E})$ : The energy composition ration of fat to total energy; Carbohydrate $(\% \mathrm{E})$ : The energy composition of carbohydrate to total energy

C group. The energy intake in our data was lower by $200 \mathrm{kcal}$ than the results presented by the National Health and Nutrition Survey in Japan, although it was not strictly comparable because of the different methods used (MoHWL 2017).

On the other hand, the intake of dietary fiber was lower in the MO group than in the $\mathrm{C}$ group by $18 \%$, although there was insignificance $(p=0.06)$ between them. Low dietary fiber intake might cause accumulation of fat in the MO group with the same energy intake as the control group (Table 3).

There were no differences between the two groups in sodium and potassium intakes; however, calcium, iron, and copper intakes tended to be lower in the MO group than in the control, 
and magnesium intakes were significantly higher in the MO group than in the control. With respect to vitamins, the MO group tended to have less vitamins, especially significantly less biotin.

\section{Relationship between body fat percentage and food intake}

The correlation between the percentage of body fat and intakes of food groups such as vegetables or beans (Table 4) were examined in all subjects. There were significant and negative correlations between body fat percentage and intakes of vegetables and beans, respectively; a higher body fat percentage was associated with lower intakes of vegetables and beans.

There are many research studies on the correlation between the intakes of vegetables and fruits and the percentage of body fat. In Japan, the subjects with masked obesity consumed a smaller daily intake of green and yellow vegetables and light-colored vegetables, and they consumed fried foods more frequently than those with standard proportions (Takeda et al. 2017). In Canada, surveys of Atlantic areas where obesity frequently emerged suggested that lower consumption of vegetables and fruits was inversely associated with visceral fat, and higher consumption of vegetables and fruits was associated with lower body fat mass (Yu et al. 2017). In a systematic review, increased vegetable consumption caused weight loss and was associated with reduced risks of becoming overweight and obese (Nour et al. 2018).

There was also a significant negative correlation between soy intake and body fat
Table 4. Correlation between body fat percentage and intake of vegetables and beans

\begin{tabular}{lccc}
\hline \multirow{2}{*}{ Food group } & \multicolumn{3}{c}{ Body fat percentage } \\
\cline { 2 - 4 } & $\mathrm{n}$ & $\mathrm{r}$ & $\mathrm{p}$ \\
\hline Vegetables & 131 & -0.17 & 0.049 \\
Beans $^{*}$ & 131 & -0.22 & 0.012 \\
${ }^{*}$ Tofu, natto, atsuage, etc & & &
\end{tabular}

Pearson

percentage, indicating that higher soy intake was associated with lower body fat percentage (Table 4). This suggests that soy protein contains peptides that reduce body fat. Experimentally, it has been shown that consumption of soy protein reduces body weight and body fat mass in addition to lowering plasma cholesterol and triglycerides in humans and rats (Velasquez et al. 2007). Thus, the lower body fat percentage may be due to the body fat-lowering effect of soybean protein when bean intake was high.

Therefore, the results suggest that unhealthy dietary habits such as the low intake of vegetables and soybeans might accelerate body fat accumulation and then lead to formation of masked obesity.

\section{Comparison of exercising habits and dieting experiences between the MO and $\mathrm{C}$ groups}

In lifestyle habits, $31.4 \%$ and $56 \%$ of the $\mathrm{MO}$ and $\mathrm{C}$ groups, respectively, reported having present exercise habit (Table 5). However, there was no difference between the $\mathrm{MO}$ and $\mathrm{C}$ groups in their past exercise habit. Accumulation of body fat may be attributable to excessive energy

Table 5. The percentage of the subjects with dieting experiences, present exercise habit and past exercise habit in masked obesity groups and control groups

\begin{tabular}{lcccc}
\hline Dieting experiences and exercise habit & $\begin{array}{c}\mathrm{MO} \\
\mathrm{n}(\%)\end{array}$ & $\begin{array}{c}\mathrm{C} \\
\mathrm{n}(\%)\end{array}$ & $\begin{array}{c}\text { Total } \\
\mathrm{n}(\%)\end{array}$ & $\mathrm{p}$ value \\
\hline Dieting experiences & & & & \\
$\quad$ Yes & $27(77.1 \%)$ & $34(45.3 \%)$ & $61(55.5 \%)$ & $<0.01$ \\
$\quad$ No & $8(22.9 \%)$ & $41(54.7 \%)$ & $49(44.5 \%)$ & \\
Present exercise habit & & & & \\
$\quad$ Yes & $11(31.4 \%)$ & $42(56.0 \%)$ & $53(48.2 \%)$ & 0.02 \\
$\quad$ No & $24(68.6 \%)$ & $33(44.0 \%)$ & $57(51.8 \%)$ & \\
Past exercise habit & & & & \\
$\quad$ Yes & $31(88.6 \%)$ & $62(82.7 \%)$ & $93(84.5 \%)$ & 0.43 \\
$\quad$ No & $4(11.4 \%)$ & $13(17.3 \%)$ & $17(15.5 \%)$ & \\
\hline MO: Masked Obesity group; C. Control group & & & &
\end{tabular}


intake or physical inactivity (Weinsier et al. 2002). As energy intake of the MO group was almost the same as that of the $\mathrm{C}$ group (Table 3 ), less physical activity may easily lead to masked obesity (Table 5).

Dieting behaviors for thinness are thought to contribute to masked obesity (Mase et al. 2012). In the present study, $77 \%$ of the subjects in the MO group had dieting experiences, which was much higher than the $45 \%$ in the $\mathrm{C}$ group. Therefore, inappropriate dieting behaviors would be a risk factor for masked obesity in young persons with normal BMI because dieting in people with a normal physique might induce a greater loss of fat-free mass rather than fat (Dulloo \& Jacquet 1999).

Physical inactivity was also strongly associated with FFM. FFM of the MO group was somewhat lower compared with that of the $\mathrm{C}$ group. Since muscle, the main part of the fatfree mass, is the largest tissue for burning fat, the decline in fat-free mass results in a substantial tissue reduction that burns fat (Dulloo\&Jacquet 1999).

\section{Seasonal changes in the prevalence of masked obesity}

The prevalence of masked obesity was $48 \%$ in winter, $36 \%$ in spring and summer, and
$40 \%$ in autumn (Figure 2). There were seasonal changes in the prevalence of masked obesity with the highest frequency in winter and the lowest frequency in spring and summer.

High body fat in winter is in accordance with the physiological mechanisms that adapt to cold by increasing the amount of subcutaneous fat in winter (Ishigure et al. 1980) (Glaser \& Shephard 1963), suggesting that seasonal changes need to be considered and investigated in studies of masked obesity.

\section{Strengths and limitations}

Seasonal changes in the prevalence of MO have never been examined in previous studies; we addressed this gap and found the highest prevalence of $\mathrm{MO}$ in winter, with most subjects likely to be associated with poor exercise, inappropriate dieting experiences, and unhealthy dietary habits. Exercise and healthy food intake reduce accumulation of body fat, thus preventing MO. Therefore, measurement of body fat mass in body composition is essential for enhancing awareness about MO among those with normal body weight.

This study, however, has some limitations as well. First, the subjects do not include men. Second, the subjects were all in the narrow age range of 21 to 22 years. Third, the participants

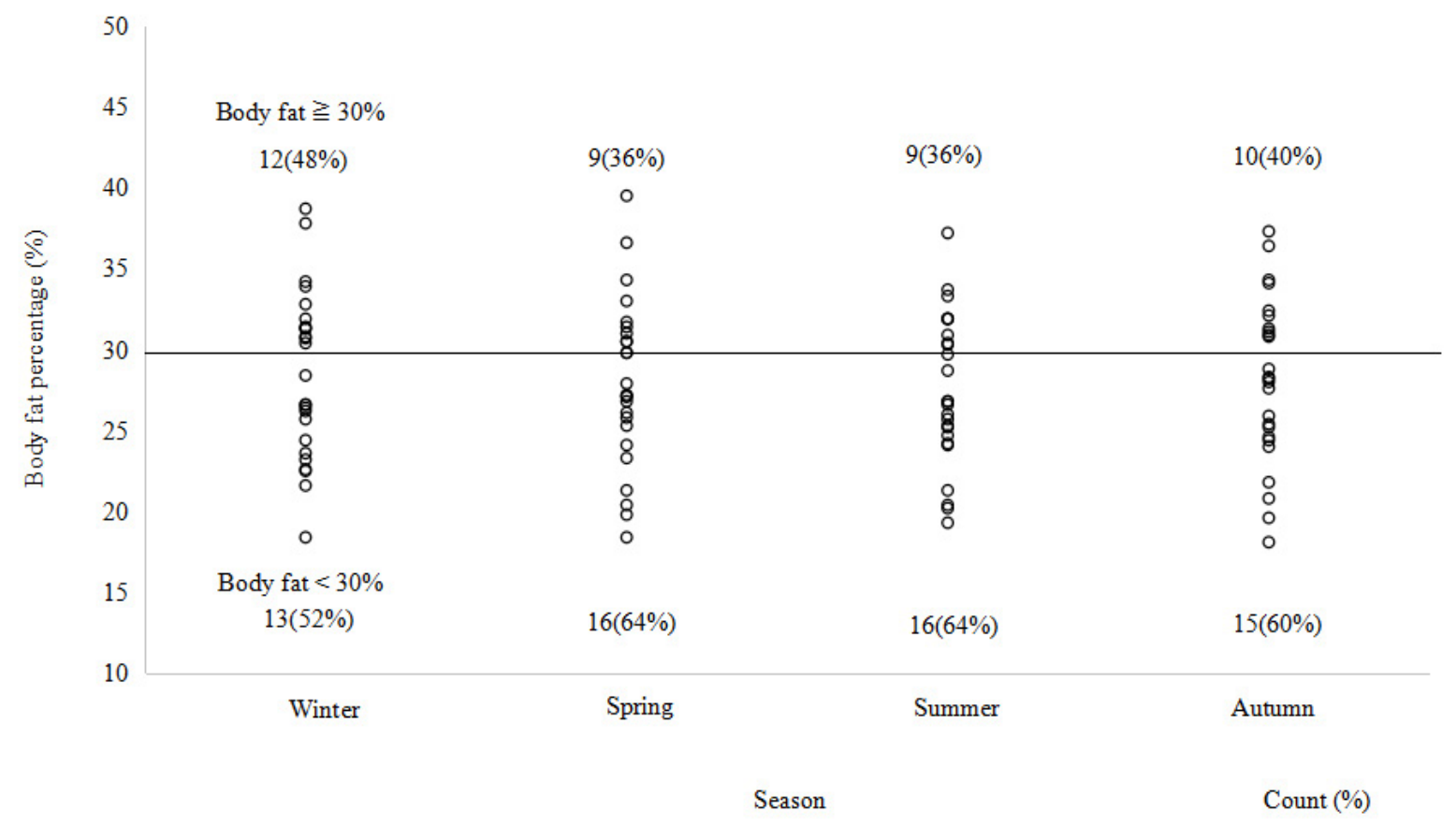

Figure 2. Seasonal changes in prevalence of masked obesity 
were all (a) educated, (b) versed in the field of home economics, (c) women in a university, and (d) lived in urban areas. Thus, the results on a single population may not necessarily reflect physical condition of young women in general.

\section{CONCLUSION}

Masked obesity was found in about $32 \%$ of young women with normal BMI values in our spring study. There were seasonal changes in the prevalence of masked obesity with the highest frequency in winter and the lowest frequency in spring and summer. It was shown that the body composition of subjects with masked obesity consisted of low levels of fat-free mass and high levels of body fat, accumulated widely in the trunk, upper limbs, and lower limbs. Dietary habits with low vegetable and soy protein intake may accelerate body fat accumulation. Additionally, it was also speculated that the low FFM was due to inappropriate dieting and less exercising. Studies of masked obesity need to also consider seasonal changes.

\section{ACKNOWLEDGEMENT}

This research was supported by a grant for research from Kobe Women's University and partly by Grant-in-Aid for Science Research of the Ministry of Education, Culture, Sports, Science and Technology of Japan (no. 25350162).

\section{AUTHOR DISCLOSURES}

The authors have no conflict of interest.

\section{REFERENCES}

Akil M, Top E. 2019. Obesity awareness and nutrition behavior of school children in Usak Province, republic of Turkey. J Gizi Pangan 14(1): 1-8. https://doi. org/10.25182/jgp.2019.14.1.1-8 .

Cha K, Chertow GM, Gonzalez J, Lazarus JM, Wilmore DW. 1995. Multifrequency bioelectrical impedance analysis estimates the distribution of body water. J Appl Physiol 79(4):1316-1319. https://doi. org/10.1152/jappl.1995.79.4.1316.

Dulloo AGJ, Jacquet J. 1999. The control of partitioning between protein and fat during human starvation: It's internal determinants and biological significance. Br J Nutr 82(5):339-359. doi: https://doi. org/10.1017/S0007114599001580.

Fukuoka Y, Ueoka H, Koya N, Fujisawa Y, Ishii M. 2012. Anthropometric method for determining "Masked obesity" in the young Japanese female population. Journal of Anthropology 2012:5 pages .doi:10.1155/2012/595614.

Glaser EM, Shephard RJ. 1963. Simultaneous experimental acclimatization to heat and cold in man. J Physiol 169(3): 592-602. doi: 10.1113/jphysiol.1963.sp007282.

Ishigure K, Ohki J, Shibata J. 1980. Skinfold thickness observed on students in a women's college with special reference to the seasonal variation and the effect of the activities in the athletic clubs. J Physical Fitness Japan 29(4):205-212. https://doi. org/10.7600/jspfsm1949.29.205.

Malavolti M, Mussi C, Poli M, Fantuzzi AL, Salvioli G, Battistini N. 2003. Crosscalibration of eight-polar bioelectrical impedance 3 analysis versus dual-energy $\mathrm{x}$-ray absorptiometry for the assessment of total and appendicular body composition in healthy subjects aged 21-82 years. Ann Hum Bio 130(4):380-391. https://doi.org/1 0.1080/0301446031000095211.

Mase T, Miyawaki T, Kouda K, Fujita Y, Okita Y, Ohara K, Mimasa F, Nakamura H. 2012. [Association between normal weight obesity and diet behaviors in female students]. Japanese Journal of Public Health 59(6):371-380.

McKiney K, Breitkopft CR, Berenson AB. 2008. Association of race, body fat and season with vitamin $\mathrm{D}$ status among young women: A cross-sectional study. Clin Endocrinol 69(4) :535-541. https://doi. org/10.1111/j.1365-2265.2008.03233.x.

[MoHWL] Ministry of Health and Welfare Labour. 2017. The national health and nutrition survey in Japan, https://www.mhlw.go.jp/ stf/houdou/0000177189 00001.html. [Accessed 18th June 2019].

Must A, Jacques PF, Dallal GE, Bajema CJ, Dietz WH. 1992. Long-term morbidity and mortality of overweight adolescents. A follow-up of the Harvard growth study of 1922-1935. N Engl J Med 327(19):1350-1355. doi: 10.1056/ NEJM199211053271904. 
Nour M, Lutze SA, Grech A, Allman-Farinelli M. 2018. The relationship between vegetable intake and weight outcome: A systematic review of cohort studies. Nutrients 10(11):1626. https://doi.org/10.3390/ nu10111626.

Oguri K, Kato Y, Kurokawa J, Inoue H, Watanabe I, Matsuoka T. 2006. Serum lipid levels in male and female high school freshmen with masked obesity. Japanese J Phys Fit Sports Med 55(1):155-164.

Takahashi R, Ishii M, Hukuoka Y. 2002. A method for evaluating the masked obesity in young females. Japan Society of Physiological Anthropology 7(4):213-217.

Takeda M, Koizumi H, Emori Y. 2017. An exploratory study of the lifestyles of female students and masked obesity in two colleges in the Kanto area. An Official Journal of the Japan Primary Care Association 40(1):2-8. https://doi. org/10.14442/generalist.40.2.

Utter AC, Lambeth PG. 2010. Evaluation of multifrequency bioelectrical impedance analysis in assessing body composition of wrestlers. Med Sci Sports Exerc 42(2):361-367. doi: 10.1249/ MSS.0b013e3181b2e8b4.

Velasquez MT, Bhathena SJ. 2007. Role of dietary soy protein in obesity. Int $\mathrm{J}$ Med Sci 4(2):72-82. doi: 10.7150/ijms.4.72.
Weinsier RL, Hunter GR, Schutz Y, Zuckerman PA, Darnell BE. 2002. Physical activity in free-living, overweight white and black women: Divergent responses by race to diet-induced weight loss. Am J Clin Nutr 76(4):736-742. https://doi.org/10.1093/ ajcn/76.4.736.

[WHO] World Health Organization Expert Consultation. 2004. Appropriate bodymass index for Asian populations and its implications for policy and intervention strategies. Lancet 363(9403):157-163. doi: 10.1016/S0140-6736(03)15268-3.

Yoshiike, N, Seino F, Tajima S, Arai Y, Kawano M, Furuhata T, Inoue S. 2002. Twenty-year changes in the prevalence of overweight in Japanese adults: The national nutrition survey 1976-95. Obes Rev 3(3):183-190. doi: 10.1046/j.1467-789x.2002.00070.x.

Yu ZM, DeClerq V, Cui Y, Forbes C, Grandy S, Keats M, Parker L, Sweeney E, Dummer TJB. 2017. Fruit and vegetables intake and body adiposity among populations in Eastern Canada: The Atlantic partnership for tommorow's health study. BMJ Open 8(4): e018060. doi :10.1136/ bmj open 2017-018060.

Yumigeta R, Tsunoda N, Horikawa H. 2015. The part difference of Change of body fat in Japanese young women. Jpn J Health Hum Ecol 81(3):75-81. doi: 10.3861/ jshhe.81.75. 